\title{
AGROTRILHA NA CAATINGA: INSTRUMENTO PIONEIRO PARA O TURISMO RURAL E ESTRATÉGIA DE EDUCAÇÃO AMBIENTAL
}

\author{
Magda Maria Guilhermino ${ }^{1}$ \\ Ana Beatriz Gomes Ferreira ${ }^{2}$ \\ Silvânia Melo da Cunha ${ }^{3}$ \\ Sueli Aparecida Moreira ${ }^{4}$
}

Resumo: O agroturismo representa uma oportunidade de Educação Ambiental em áreas degradadas da Caatinga. Naquele contexto, o presente estudo tem como objetivo avaliar a viabilidade de uma trilha ecológica construída em conjunto aos agricultores familiares para demonstrar ações de recuperação do solo, utilizando estruturas de pedras e vegetativas para a recuperação do solo. Portanto, realizouse pesquisa-ação na comunidade Trangola em Currais Novos (RN), para avaliar o potencial turístico da comunidade e a eficácia da trilha em Educação Ambiental. Concluiu-se que o agroturismo representa uma estratégia de desenvolvimento sustentável da comunidade ao viabilizar a agricultura familiar. A trilha pode assegurar renda alternativa enquanto se promove a restauração do bioma da Caatinga.

Palavras-chave: Agroecologia; Turismo Rural; Hospitalidade Sertaneja; Desenvolvimento da Comunidade.

Abstract: Agrotourism represents an opportunity for environmental education in degraded areas of the Caatinga. In that context, this study aims to evaluate the feasibility of an ecological trail built together with family farmers to demonstrate the actions of soil recovery using stone and vegetative structures for soil recovery. Therefore, action research was carried out in the Trangola community in Currais Novos (RN, Brazil), to evaluate the tourism potential of the community and the effectiveness of the trail in environmental education. It was concluded that agrotourism represents a sustainable development strategy of the community, by enabling family farming. The trail can ensure alternative income while promoting the restoration of the Caatinga biome.

Keywords: Agroecology; Rural Tourism; Country Hospitality; Community Development.

\footnotetext{
1Universidade Federal do Rio Grande do Norte (UFRN). E-mail: magdaguilhermino@gmail.com, Link para o Lattes: http://lattes.cnpq.br/2481533325379100.

2Universidade Federal do Rio Grande do Norte (UFRN). E-mail: beatriz biologia@hotmail.com, Link para o Lattes: http://lattes.cnpq.br/3428643449624579.

${ }^{3}$ Universidade Federal do Rio Grande do Norte (UFRN). E-mail: silvaniamelo0508@gmail.com.br, Link para o Lattes: http://lattes.cnpq.br/9958317186143829.

${ }^{4}$ Universidade Federal Rural do Rio de Janeiro (UFRRJ). E-mail: suelimoreira@yahoo.com.br, Link para o Lattes: http://lattes.cnpq.br/9469781068838287.
} 


\section{Introdução}

O agroturismo foi definido pelo programa de pequenas propriedades da Universidade da Califórnia como sendo "um empreendimento comercial em uma fazenda, rancho ou fazenda agrícola conduzido para o desfrute de visitantes que gerava renda suplementar para o proprietário". O conceito era uma mistura de integração agrícola e lazer. Da perspectiva dos moradores da cidade, eles poderiam passar seu tempo livre em harmonia com a natureza e desfrutar dos hábitos da vida rural a um custo acessível (KAPADIA, 2018).

As trilhas ecológicas são planejadas para sensibilizar o visitante para algum aspecto da natureza durante o lazer. A percepção ambiental inclui observar, sentir, experimentar, questionar, refletir e descobrir as peculiaridades da vegetação, da fauna, relevo e do solo (SILVEIRA; MELO, 2009). Além do mais podem ser interpretativas ou cênicas, auto interpretativas ou autoguiadas. Percursos de curta distância facilitam a compreensão das características naturais e/ou construídas da sequência paisagística apresentada durante 0 traçado (LIMA, 1998).

Trilhas agroecológicas também foram implantadas como instrumento pedagógico de aprendizagem e forma de educação socioambiental para incentivar a observação e a reflexão na formação de uma consciência crítica sobre o meio ambiente (BRASIL, 2018).

O agroturismo representa uma oportunidade de Educação Ambiental (EA) e a proposta de uma agrotrilha compreende a visitação turística dos locais de recuperação de bioma através de ações e tecnologias para reintrodução da agricultura familiar na Caatinga. Ela também mostra as ações agroecológicas de recuperação do solo da Caatinga. Assemelha-se a uma trilha ecológica, no entanto é específico para regiões áridas e semiáridas.

A terminologia "agrotrilha" surgiu durante a execução do projeto Defeso da Caatinga, projeto multidisciplinar e interinstitucional que trata da construção de uma política pública, conforme Guilhermino et al. (2019). O projeto Defeso da Caatinga visa à recuperação do bioma Caatinga e o desenvolvimento sustentável da agricultura familiar através do protagonismo da comunidade sertaneja (GUILHERMINO et al. 2019).

O processo de recuperação de áreas degradadas da Caatinga passa por ações de extensão rural constante e de qualidade. A implementação envolve a mobilização e motivação dos agricultores, fornecimento de orientação técnica para a construção e monitoramento de tecnologias agroecológicas de conservação de solos, como renques, barramentos, raleamento e rebaixamento de Caatinga, conforme as recomendações de Araújo Filho (2002) e de Lira Santos et al. (2007).

As tecnologias agroecológicas são métodos simples e eficientes no combate à desertificação, de baixíssimo custo e podem ser feitas manualmente e de forma coletiva, além de que se mostram verdadeiras obras de arte ao longo das áreas a serem recuperadas (LIRA-SANTOS et al. 2007). 
A visitação turística em unidades rurais familiares pode tornar possível o desenvolvimento sustentável da agricultura familiar. Diante deste contexto, empregando o turismo rural para revelar a paisagem do bioma Caatinga, desenvolveu-se o presente estudo com objetivo de avaliar a potencialidade da comunidade Trangola para o agroturismo e a viabilidade da agrotrilha como estratégia de Educação Ambiental.

\section{Referencial Teórico}

\section{Agroturismo e desenvolvimento regional}

A modalidade do agroturismo ou turismo rural surgiu na Europa no ano de 1960 e está presente em diversos países, com diferentes denominações e características, sendo compreendida como uma atividade que ocorre em propriedades com exploração agropecuária, integrada a uma propriedade rural ativa, de organização e gestão familiar, como complemento de renda; proporciona a participação direta do turista nas atividades rotineiras no meio rural (GIL, 1994; PARRA et al., 2006).

No Brasil, o agroturismo teve início no final da década de 80 , no estado do Espírito Santo com o "Programa de Agroturismo" criado com a finalidade de implantar ações em parceria com as famílias das unidades rurais. Para desenvolver atividades como utilizar de maneira integral a produção das fazendas, as paisagens bucólicas, à cultura, a culinária regional, a hospitalidade, como atrativos turísticos dos núcleos de agricultores, tornando o agroturismo uma modalidade de turismo praticado no meio rural (PARRA et al., 2006).

Vários fatores contribuíram para o desenvolvimento turístico e da modalidade do agroturismo. A maioria das experiências ou vivências turísticas em espaços rurais ocorreu devido às crises agrárias, a redução do fluxo de turismo internacional e a sobrecarga no turismo litorâneo que contribuíram para incentivar o turismo nas regiões mais interioranas ou continentais onde se tornou prática comum hospedar turistas em fazendas e ranchos (SANTOS; SOUZA, 2010).

De acordo com Francisco Junior (1999), o turismo em áreas rurais tende a ser uma nova opção de complemento de renda e desenvolvimento regional. Segundo o autor, a atividade remunerada pode manter o agricultor em seu ambiente habitual além de despertar o interesse em conservar os patrimônios naturais e as tradições locais.

\section{Agroturismo como estratégia de Educação Ambiental}

O turismo em espaços rurais, aqui denominado agroturismo, considera imprescindível a preservação da biodiversidade e não somente dos ecossistemas naturais, mas também dos valores culturais relacionadas aos grupos sociais (SEABRA, 2007).

Com relação aos benefícios ambientais motivados pela prática do agroturismo, destaca-se o estímulo à conservação ambiental e à multiplicação 
de espécies de plantas e animais endêmicos, garantindo a proteção dos bens naturais e das funções ecossistêmicas, atrelados à demanda de turistas que buscam usufruir de serviços ecologicamente responsáveis.

O turismo responsável é planejado em conformidade aos princípios de desenvolvimento sustentável de Veiga (2005): socialmente includente, ambientalmente sustentável e economicamente sustentado.

A definição de Educação Ambiental (EA) foi instituída pela Política Nacional de Educação Ambiental sancionada na Lei oㅜ 9.795, de 27 de abril de 1999:

Art, $1^{\circ}$ Entendem-se por Educação Ambiental os processos por meio dos quais o indivíduo e a coletividade constroem valores sociais, conhecimentos habilidades, atitudes e competências voltadas para a conservação do meio ambiente, bem como uso comum do povo, essencial à sadia qualidade de vida e sua sustentabilidade.

Art $2^{\circ}$ A Educação Ambiental é um componente essencial e permanente da educação nacional [...].

Art $3^{\circ}$ Como parte do processo educativo mais amplo, todos têm direito à Educação Ambiental [...] (MMA, 27 de abril de 1999).

A Educação Ambiental (EA) tem o objetivo de destacar a importância do convívio equilibrado entre o homem e o meio ambiente, pensando o ser humano como parte integrante da natureza e, portanto, inserido em todos os processos ecológicos (DE MOURA CARVALHO, 2017). A devida compreensão dos hábitos de consumo favorece o ajuste da convivência humana com a natureza por meio de atitudes sustentáveis. Logo, se discute o papel da agrotrilha no âmbito da EA, e como essa ferramenta pode ajudar nos conceitos sobre a natureza e o papel da sociedade sobre ela.

\section{Tecnologias de recuperação do bioma Caatinga}

A paisagem bucólica do bioma Caatinga é usada para compor os atrativos da agrotrilha, dentro de um contexto do sertão. A Caatinga é uma vegetação típica de clima semiárido e este bioma é exclusivamente brasileiro. $O$ relevo da Caatinga apresenta duas formações dominantes, os planaltos e as grandes depressões, formados de fragmentos de rocha (LEAL; TABARELLI; DA SILVA, 2003; MAIA, 2004). O bioma Caatinga é rico em recursos genéticos, apresenta fauna e flora endêmicas, formando uma vasta biodiversidade e que foram apresentados como atrativos aos turistas como parte fundamental da biodiversidade dos ecossistemas (DA SILVA; LEAL; TABARELLI, 2018). A Caatinga ocupa $11 \%$ do território nacional, porém é a menos conhecida cientificamente e apresenta espécies endêmicas ameaçadas de extinção. De acordo ao MMA (2010) mais de 50\% deste bioma foi desmatado por ações antrópicas, dentre as quais podemos citar atividades predatórias de agricultura e pecuária, mineração, produção de lenha, cerâmica e extração para 
construção civil. Este desmatamento tem causado a lixiviação dos solos, processos de erosão e o assoreamento dos corpos d'água levando a degradação ambiental que vem contribuindo para o processo de desertificação que assola a região semiárida.

Tecnologias de recuperação do bioma Caatinga compreendem um conjunto de ações preventivas ao desmatamento, erosão e o assoreamento e que promovam a recuperação dos solos e a revegetação devem ser incentivadas e valorizadas por toda a sociedade (LIRA-SANTOS et al., 2007).

Atividades antrópicas envolvendo a exploração agropecuária acarreta o desmatamento, tornando os solos desprovidos de cobertura vegetal. Então, quando as chuvas caem nessas áreas desmatadas onde deveria haver mata ciliar, carreiam a camada superficial de solo e de matéria orgânica, aterrando os corpos d'água, principalmente leitos dos rios, diminuindo o volume hídrico que poderia ser por ele armazenado, além de diminuir a camada fértil do solo, tornando-o infértil e impróprio para o plantio.

Tecnologias agroecológicas compreendem renques, barramentos, enleiramentos de estruturas vegetativas provenientes da poda e/ou raleamento e rebaixamento de árvores. Durante o processo de recuperação de solos, essas técnicas são eficientes e efetivas no combate à desertificação e servem para evitar que a matéria orgânica chegue até os leitos do rio, prevenindo o assoreamento. Além disso, essas tecnologias são de baixíssimo custo e podem ser feitas manualmente e de forma coletiva (LIRA-SANTOS et al., 2007).

Os renques de pedra são cordões pedregosos em curva de nível, inseridos em lugares estratégicos para a contenção de solo em áreas desmatadas; os renques de galho, improvisados de estruturas vegetativas, são feitos com material proveniente da poda inteligente e/ou rebaixamento da vegetação lenhosa do bioma Caatinga. Essa poda tem o objetivo de retirar galhos que causam prejuízo energético à planta na época de escassez hídrica.

Esse material vegetativo é agrupado na forma de renques em curva de nível ou colocado no "pé das árvores" para manter a umidade e melhorar o aporte de matéria orgânica no solo (LIRA-SANTOS et al., 2007).

Os barramentos são feitos nos leitos dos corpos d'água, córregos ou riachos de microbacias ou caminhos de enxurradas que apresentam elevada declividade e são essenciais para evitar o assoreamento de rios da região (LIRA-SANTOS et al., 2007).

O raleamento é uma prática de manipulação da vegetação nativa arbóreo-arbustiva da Caatinga que consiste em retirar as plantas em excesso (poda inteligente), incluindo o controlando seletivo de espécies lenhosas, reduzindo a densidade da vegetação e do sombreamento, permitindo que as sementes das plantas herbáceas germinem e se desenvolvam. O raleamento transfere a produção de biomassa (a poda dos arbustos e árvores) para o estrato herbáceo aumentando consideravelmente a matéria seca, o que possibilita a produção de alimentos de origem animal e vegetal. Consiste em uma estratégia para uso sustentável da vegetação da Caatinga.

revista brasileira educação ambiental 
O rebaixamento trata-se de cortar as espécies lenhosas a uma altura de 30 a $40 \mathrm{~cm}$ do solo (popularmente conhecida como Broca), no terço final do período de estiagem para que as plantas possam rebrotar no início das chuvas, disponibilizando massa verde dos arbustos e árvores, podendo ser utilizada pelos caprinos que poderão pastejar sem danificar as arvores e sem exaurir a vegetação (ARAÚJO FILHO et al., 2007).

Apresentar à comunidade de agricultores familiares um conjunto de tecnologias de recuperação da Caatinga promove a conservação e o uso sustentável dos recursos florestais do bioma por meio de demonstrações e práticas de EA. Além disso, o envolvimento com turismo rural ou agroturismo confere oportunidade de renda enquanto se restabelece a agricultura familiar como modo de sustento no bioma Caatinga.

\section{Métodos}

\section{Área de estudo}

A agrotrilha foi desenvolvida no assentamento Trangola (Figura 1), localizado no na região do Seridó, estado do Rio Grande do Norte. A comunidade conta com 11 famílias com o total de 37 pessoas, cuja renda advém da agricultura familiar. Toda a propriedade possui extensão de $12 \mathrm{~km} 2 \mathrm{e}$ está localizada a $23 \mathrm{~km}$ do Centro do município de Currais Novos $\left(05^{\circ}{ }^{16}{ }^{\prime}\right.$ 22"S-35 '22'57"W), no estado do Rio Grande do Norte, semiárido nordestino, Brasil. A agrotrilha tem a extensão de $5.2 \mathrm{~km}$ e foi inaugurada em 24 de junho de 2017, durante um dia de campo intitulado Estação Trangola.

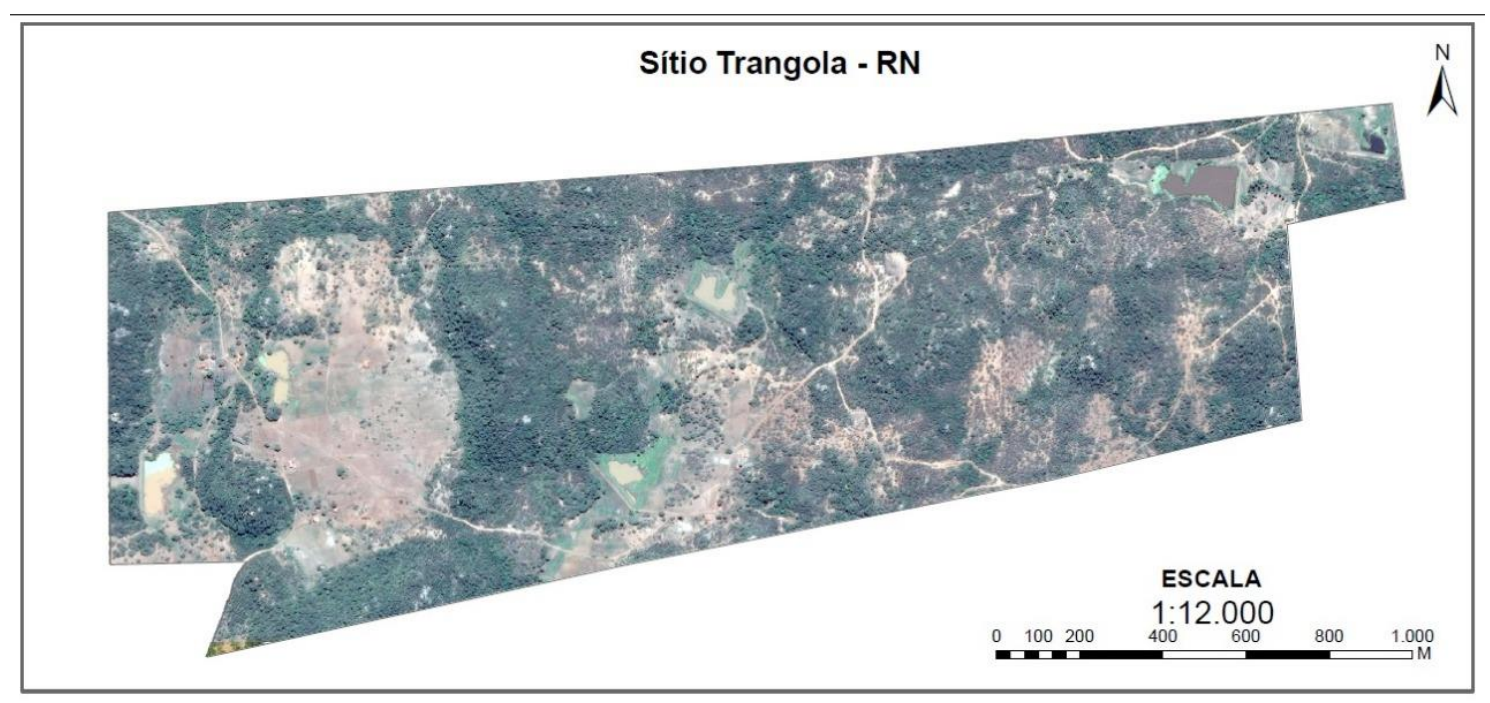

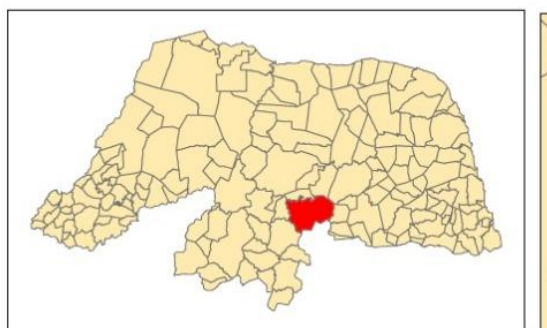

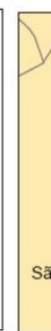

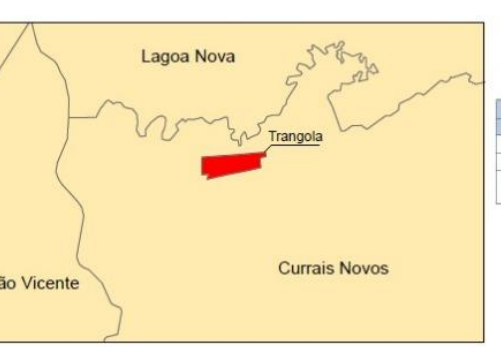

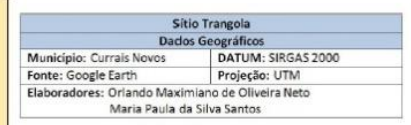

Figura 1: Localização do Sítio Trangola, Currais Novos (RN). Fonte: Google Earth, 2018. 


\section{Procedimentos metodológicos}

Por interesse mútuo entre comunidade e universidade realizou-se uma pesquisa ação para avaliar a viabilidade da agrotrilha e constatar sua eficácia como estratégia de Educação Ambiental. Uma pesquisa ação, cuja abordagem favoreceu a aproximação entre teoria (planejamento turístico) e prática. A pesquisa ação consiste em processo colaborativo entre pesquisadores e sujeitos, cujo objetivo é incorporar novos processos de conhecimento, estabelecer padrões éticos e de qualidade (SOMEKH; LEWIN, 2015).

A pesquisa-ação foi desenvolvida por equipe interdisciplinar da UFRN em três etapas. A primeira fase de interação no local envolveu a troca de saberes entre universidade e comunidade, com o objetivo de fortalecer a autonomia da comunidade para gerir o processo. Na segunda fase, foram implementadas cinco tecnologias para recuperação do bioma Caatinga, cuja evolução permitiu a recuperação do solo para retomada da agricultura de base familiar. A terceira etapa consistiu na proposição do turismo rural através da construção de uma agrotrilha como estratégia de EA, promoção da recuperação da Caatinga e do desenvolvimento local por meio do turismo.

Foi analisada a viabilidade de implementar a agrotrilha no contexto sertanejo na comunidade Trangola durante a inauguração da visita guiada que contava com uma bióloga e um membro responsável pelo assentamento devidamente credenciado como guia. Ao término do percurso, 13 participantes concordaram em responder ao formulário aplicado individualmente durante entrevista.

Antes de cada entrevista era realizada a leitura do Termo de Consentimento Livre e Esclarecido (TCLE), conforme a Resolução do Ministério da Saúde CNS 510 de 2016, explicando os objetivos, esclarecendo possíveis dúvidas, enfatizando a importância da participação para o desenvolvimento da pesquisa e garantindo o uso somente para fins acadêmicos.

\section{Resultados e Discussão}

\section{Perfil sociodemográfico}

O estudo envolveu 13 atores chaves, participantes da primeira agrotrilha da comunidade Trangola. Os entrevistados são de diferentes espaços sociais de Currais Novos e outras regiões do Rio grande do Norte, aludidas por nomes fictícios, cujas profissões são distintas. Dos entrevistados 5 são estudantes de nível superior de diferentes regiões do Estado do RN, 4 entrevistados são funcionários públicos do Município de Currais Novos de diferentes departamentos, 1 professor de ensino básico da rede pública, 1 técnico agrícola, 1 jornalista e 1 guia de turismo. Os participantes encontravamse na faixa etária entre 22 e 51 anos de idade (Quadro 1). 
Quadro 1: Perfil dos entrevistados que avaliaram a agrotrilha Trangola. Currais Novos, 2017.

\begin{tabular}{|c|c|c|c|}
\hline Raquel & 30 anos & Estudante & Natal/RN \\
\hline Caio & 27 anos & Estudante & Nísia Floresta/RN \\
\hline Fernanda & 22 anos & Estudante & Parnamirim/RN \\
\hline Aline & 27 anos & Estudante & Natal/RN \\
\hline Maria & 32 anos & Estudante & São Gonçalo do Amarante/RN \\
\hline Aurélio & 51 anos & Professor & São José do Seridó/RN \\
\hline Pereira & 39 anos & Técnico agrícola & Parelhas/RN \\
\hline Martins & 34 anos & Jornalista & Natal/RN \\
\hline Kely & 29 anos & Guia de Turismo & Currais Novos/RN \\
\hline Juliana & 37 anos & Funcionária Pública & Currais Novos/RN \\
\hline Mariana & 24 anos & Funcionária Pública & Currais Novos/RN \\
\hline Andressa & 47 anos & Funcionária Pública & Currais Novos/RN \\
\hline Alice & 50 anos & Funcionária Pública & Currais Novos/RN \\
\hline Total & & $\mathbf{1 3}$ entrevistados \\
\hline
\end{tabular}

Fonte: Autoria Própria, 2018.

\section{Nos passos da agrotrilha Trangola}

Considerando a agrotrilha dentro do patamar ecológico, como práticas de EA no contexto do turismo rural, a agrotrilha apresenta aos turistas todo o encanto da paisagem do bioma Caatinga e seus benefícios ambientais como conservação da água e do solo, formas de evitar o assoreamento de rios, recuperação e revegetação das áreas degradadas do bioma, e conservação de toda sua biodiversidade. Durante o percurso da trilha com capacidade de carga de até 20 pessoas por vez e duração em média de $01 \mathrm{~h} 30 \mathrm{~min}$, diversas paradas estratégicas foram realizadas.

A organização da agrotrilha em nove estações (Quadro 2) e cada temática foi sendo abordada durante as paradas. A preleção ocorria, fazendo uso de linguagem acessível e a pausa permitia apreciar o lazer e assimilar a experiência com boa memória.

Quadro 2: Caracterização das Estações ou pontos de paradas.

\begin{tabular}{|l|l|}
\hline Pontos & \multicolumn{1}{|c|}{ Descrição/Observação } \\
\hline & $\begin{array}{l}\text { 1) Hospitalidade dos anfitriões rurais. A trilha } \\
\text { inicia-se, com uma breve introdução sobre o } \\
\text { bioma Caatinga. Breve história do Sítio Trangola } \\
\text { e sua ligação com recuperação do semiárido. }\end{array}$ \\
\hline & $\begin{array}{l}\text { 2) Apresentação da vegetação endêmica do } \\
\text { bioma Caatinga, suas características, utilidades } \\
\text { e sua importância no ecossistema. }\end{array}$ \\
\hline
\end{tabular}

Continua... 


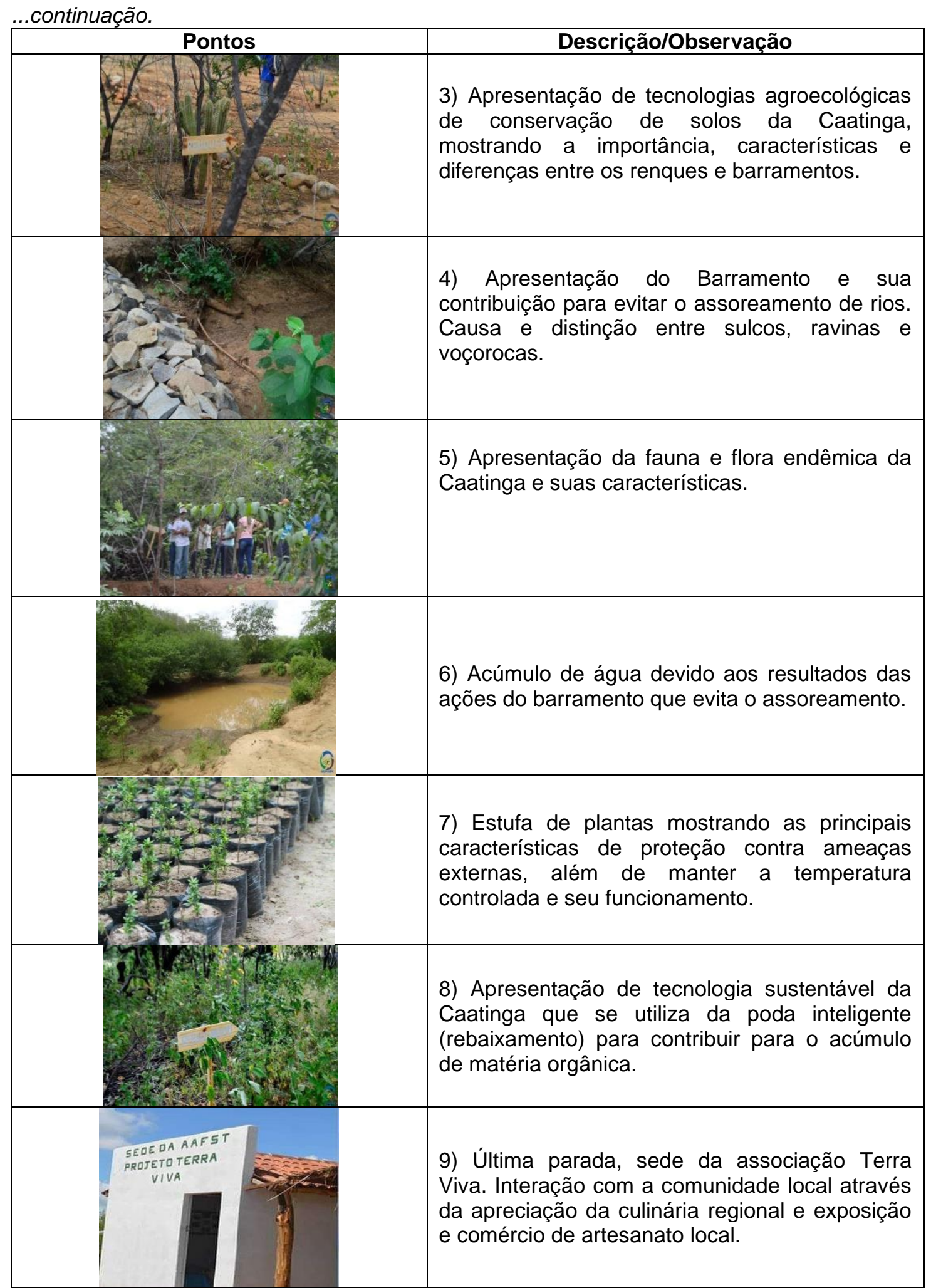

Fonte: GEPARN, 2017.

Revbea, São Paulo, V.16, № 5: 377-391, 2021. 


\section{Agroturismo como oportunidade para Educação Ambiental}

O turismo rural ou agroturismo surge como uma alternativa ao turismo de massa e ao turismo litorâneo de sol e mar. O agroturismo é considerado uma atividade nova no Brasil, ainda pouco explorada, principalmente no Nordeste. Nenhum dos entrevistados havia vivenciado uma agrotrilha. Todos apreciaram a iniciativa de forma positiva:

"Ideias e ações simples que fazem toda a diferença" (Martins, 34 anos, Jornalista);

"A Agrotrilha possibilita a compreensão do mecanismo de vida da Caatinga, bem como se desenvolve" (Raquel, 30 anos, estudante).

Segundo Guimarães (2001), a vivência na natureza constitui-se em atividade de sensibilização ambiental, envolvendo diferentes estímulos à educação através de valores ou pela identificação com a paisagem.

Durante a agrotrilha foi possível constatar diversas ações para a conservação do solo através dos renques e barramentos de pedra, raleamento (poda inteligente), rebaixamento, acúmulo da matéria orgânica, revegetação do bioma Caatinga, fauna e flora endêmica e controle de erosão.

"É possível perceber o uso sustentável do local" (Juliana, 37 anos, funcionária pública);

"A agrotrilha possibilita conhecer novas experiências de conservação do solo" (Fernanda, 22 anos, estudante).

O lazer no meio rural contribuiu para a sensibilização sobre atividades sustentáveis na Caatinga. Todos os entrevistados reconheceram a agrotrilha como oportunidade para Educação Ambiental.

\section{Viabilidade da agrotrilha como estratégia de desenvolvimento local}

Segundo Machado (2005), o turismo rural ou agroturismo busca a valorização do patrimônio cultural e natural, conservando raízes e divulgando costumes, trabalhando com a perspectiva de manutenção do homem no campo e servindo como novo segmento a ser agregado em complemento à atividade econômica da propriedade.

No contexto Caatinga, as diretrizes para o turismo sustentável, conforme proposta de Leung et al. (2019), deverão ser contempladas em todas as suas fases: da política ao planejamento e à gestão. Dentre outras prioridades estão salvaguardar as qualidades ambientais e / ou culturais que atraem turistas mantendo processos ecológicos essenciais e qualidades estéticas e espirituais e ajudando a conservar o patrimônio natural e a biodiversidade; respeitar os direitos das comunidades locais e sua 
autenticidade sociocultural, conservar sua herança cultural viva e valores tradicionais, e contribuir para a compreensão e tolerância interculturais.

O planejamento turístico adequado permite avaliar as potencialidades da comunidade e do meio ambiente. Nesse contexto, a iniciativa da agrotrilha tem como demanda a recuperação do solo e da vegetação do bioma Caatinga, mas isso requer tempo de espera para ocorrer a sedimentação de matéria orgânica, permitindo a plantação. O envolvimento dos agricultores na elaboração da trilha revela e valoriza os atrativos até então despercebidos.

Dentre as potencialidades para criação da agrotrilha destacam-se a paisagem rural singular da Caatinga; a possibilidade de incentivo ao comércio de toda produção associada ao turismo (artesanato, produtos da terra) e da gastronomia regional, que fomentam o desenvolvimento local.

Para analisar a viabilidade da agrotrilha como atrativo de turismo rural, um conjunto de atributos foi avaliado segundo o grau de importância entre os entrevistados que completaram o percurso (Figura 2):

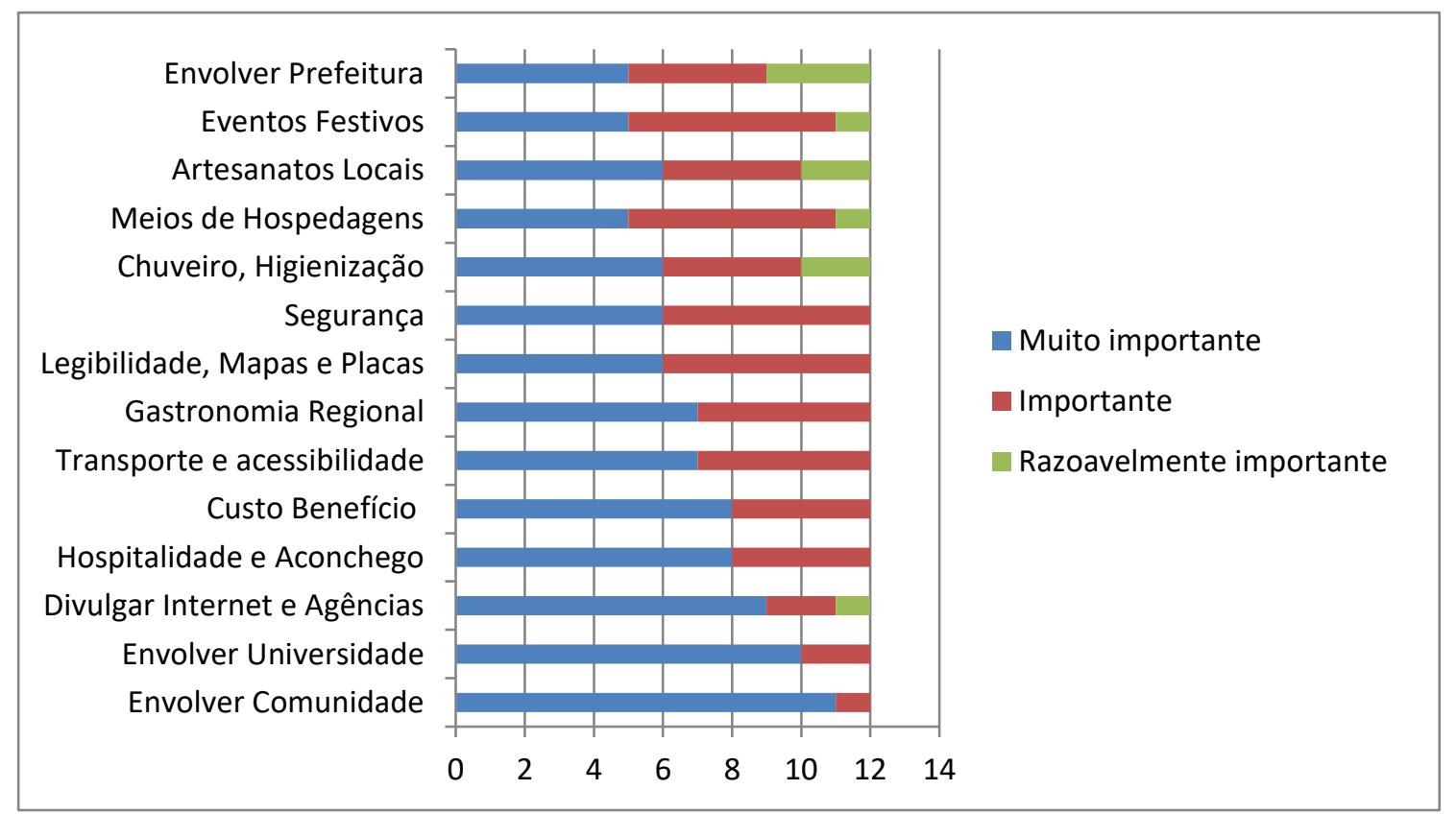

Figura 2: Atributos para efetivação da agrotrilha como atrativo rural por ordem de importância na opinião dos participantes. $n=12$. Fonte: Org. dos autores, 2018.

\section{Sugestões de melhorias para a agrotrilha}

Ao término do percurso da agrotrilha as sugestões indicadas foram: melhorar os meios de divulgação; expandir as ações abordadas durante a atividade ao torná-las práticas; melhorar a infraestrutura local, principalmente o acesso, sinalização, ponto de apoio para os visitantes/turistas; e o envolvimento da gestão municipal nesse projeto. 
"Comunicação, criação de um site para divulgação, onde os agricultores podem obter renda através da sustentabilidade" (Pereira, 39 anos, Técnico Agrícola);

"Uma maior divulgação do projeto como forma de convidar mais pessoas para conhecer as ações e estratégias de Educação Ambiental" (Martins, 34 anos, Jornalista);

"Melhorar a divulgação, como forma de chamar atenção para o incentivo à preservação ao meio ambiente" (Andressa, 47 anos, funcionária pública); "Mais divulgação!" confirmou Alice (50 anos, funcionária pública).

Quando se trata de divulgação, com base no termo "é preciso conhecer para conservar", é necessário ampliar o conhecimento. Para isso, algumas ferramentas de divulgação são necessárias e demandam investimentos em mapas locais, painéis informativos e publicidade em agências de turismo na capital com o apoio da gestão municipal.

O engajamento nas ações de recuperação do solo quando colocadas em prática durante o processo de aprendizagem reitera os princípios da Educação Ambiental e da sustentabilidade:

"Acredito ser interessante, fazer com que os visitantes tenham a oportunidade de colocar em prática as ações, ajudando na construção dos renques ou o ajudando no plantio" (Raquel, 30 anos, estudante).

Do ponto de vista da geração de renda, todos os entrevistados afirmaram que pagariam para realizar a agrotrilha, contribuindo, assim, para desenvolvimento da comunidade, manutenção da trilha e outros custos adicionais. Atividades do turismo rural como a agrotrilha pode contribuir para o fortalecimento da agricultura familiar no Assentamento Trangola.

"Para manter o lugar preservado, é necessário um controle de visitantes, e um valor para cobrir os custos da trilha" (Maria, 32 anos, estudante).

Em relação ao envolvimento do Governo Municipal através da secretaria de turismo de Currais Novos, muitos avanços são necessários, principalmente investimento na infraestrutura de acessibilidade de transporte e deslocamento ao Assentamento Trangola. É desejável, ainda, a criação de uma política municipal de turismo que contemple as demandas da comunidade local e viabilize a infraestrutura de hospitalidade para o bem receber.

"É necessário o envolvimento da secretaria de Currais Novos para melhoria das estradas rurais que dão acesso ao Trangola" (Kely, 29 anos, Guia de Turismo); "Melhorar a estrada de acesso, mobilizar o governo do município" arrematou Aurélio, (51 anos, professor). 
De acordo com dados da última questão, constatou-se que todos os entrevistados se deslocariam da cidade para realização da trilha, assim como indicariam a experiência para outras pessoas.

\section{Considerações Finais}

A proposição da agrotrilha justifica-se como uma oportunidade de atrair visitantes para o turismo rural que, além de revelar os encantos da Caatinga, demonstra aos visitantes as etapas da recuperação do Bioma, promove o lazer e o bem-estar social por meio da contemplação do projeto de recuperação de toda a área degradada, além da experiência do diálogo singular com a comunidade. Ademais, o visitante poderá adquirir desde produtos agrícolas e artesanatos da cultura local, contribuindo para a geração de renda e fortalecimento da identidade cultural local.

No contexto do município de Currais Novos, onde historicamente houve intensa exploração agropecuária, a agrotrilha é uma ferramenta de EA muito eficaz ao permitir a inserção do visitante para constatar o efeito avassalador da exploração do solo e, ao mesmo tempo, demonstra o resultado das ações de recuperação da vegetação. Todo o percurso da trilha foi planejado e manejado de modo a maximizar a sensibilização e a conscientização ambiental do visitante de todas as idades.

As ações desenvolvidas favorecem o crescimento seguro, ordenado e sustentável da agricultura familiar, preparando a comunidade para um turismo capaz de atender às expectativas da interiorização, empregando a agrotrilha como atividade econômica alternativa e como meio de propiciar, de fato, a restauração do bioma da Caatinga.

Conclui-se que a agrotrilha Trangola consiste na primeira do Brasil e diz respeito a uma série de ações de recuperação do bioma Caatinga como uma ferramenta de Educação Ambiental e estratégia de desenvolvimento da comunidade local.

\section{Referências}

ARAÚJO FILHO, J.A., DE CARVALHO, F.C., GARCIA, R., de SOUSA, R.A. Efeitos da Manipulação da Vegetação Lenhosa sobre a Produção e compartimentalização da Fitomassa Pastável de uma Caatinga Sucessional. Revista Bras. Zootec., v.31, n.1, p.11-19, 2002.

BRASIL, Constituição. Lei no 9.795, de 27 de abril de 1999. Capítulo I da Educação Ambiental. Brasília, Disponível em: < http://www.mma.gov.br/port/conama/legiabre.cfm?codlegi=321>. Acesso em: 19 de Jan de 2018.

DA SILVA, J. M. C.; LEAL, I. R.; TABARELLI, M. Caatinga: the largest tropical dry forest region in South America. Switzerland: Springer, 2018 
DE MOURA CARVALHO, I.C. Educação Ambiental: a formação do sujeito ecológico. São Paulo: Cortez Editora, 2017.

FRANCISCO JÚNIOR, J.C. Processo de desenvolvimento do ecoturismo em Brotas. I Congresso Brasileiro de Turismo (1999: Piracicaba). Anais... Piracicaba: FEALQ, p.229-233, 1999.

GEPARN. Grupo de estudo em políticas públicas para o desenvolvimento sustentável da agricultura familiar, agroecologia e recuperação do bioma Caatinga. Natal: UFRN, 2017. Disponível em $<$ http://grupogeparnufrn.blogspot.com.br/2017/06/estacao-trangola-24-dejunho-de-2017.html>. Acesso em: 26 de Dez de 2017.

GIL, F. M. Nuevas formas de turismo em los espacios rurales españoles. Estudios Turisticos, Madri, n.122, p. 15-39, 1994.

GUIMARÃES, S. T. L. Trilhas Interpretativas e Vivências na Natureza: reconhecendo e reencontrando nossos elos com a paisagem. Rio Claro: IGCE/UNESP, 2001.

GUILHERMINO, M. M., SILVA-SANTOS, M. P., CAVALARI, V. H., LICHSTON, J. E., LUCENA, R. L., BARBOSA-DE-AZEVEDO, T. K., \& MOREIRA, S. A. Defeso da Caatinga: proposta de política pública para o desenvolvimento sustentável da agricultura familiar em bioma Caatinga. Revista Brasileira De Educação Ambiental, v.14, n.2, 372-86. 2019.

KAPADIA, D. Agrotourism: enhancing and sustaining farm economy in India. Tourism and Hospitality International Journal, v. 11, n.1, p.12-25, 2018.

LEAL, I. R.; TABARELLI, M; DA SILVA, J. M. C. Ecologia e conservação da Caatinga. Recife: Editora Universitária UFPE, 2003.

LEUNG, Y-F.; SPENCELEY, A.; HVENEGAARD, G.; BUCKLEY, R; GROVES, C. Turismo e gestão da visitação em áreas protegidas: diretrizes para sustentabilidade. Gland, Switzerland: IUCN, 2019.

LIMA, S.T. Trilhas interpretativas: a aventura de conhecer a paisagem. Cadernos Paisagem, n.3, p.39-44,1998.

LIRA SANTOS, S.C., DE MEDEIROS, J.F., DE MESQUITA, L.X., DE OLIVEIRA, F. DE A., MARACAJÁ, P.B. Informativo técnico do semi-árido. Infotecnarido, v.1, n.1, p.13-27, 2007.

MACHADO, A. Ecoturismo: um produto viável: A Experiência do Rio Grande do Sul. Rio de Janeiro: Senac Nacional, 2005. 232 p.

MAIA, G. N. Caatinga árvores e arbustos e suas utilidades. São Paulo: Leitura \& Arte, 2004.

PARRA, C. S; SILVA, C. P.; CHEHADE, M. Agroturismo como fonte de renda para pequenos agricultores. Revista Científica Eletrônica Turismo, ano III, v. 3 , p. 1-7, 2006. 
SANTOS, E. de O.; SOUZA, M. Teoria e prática do turismo no espaço rural. Barueri: Manole, 2010.

SEABRA, G. Turismo sertanejo. João Pessoa: Editora Universitária UFPB, 2007.

SILVEIRA, K.; MELO, M. Uma avaliação das trilhas ecológicas do Parque Estadual de Dois Irmãos-Recife/PE. (Belém: 2009). Anais... Belém: IV Congresso de Pesquisa e Inovação da Rede Norte e Nordeste de Educação Tecnológica, 2009.

SOMEKH, B.; LEWIN C. Teoria e Métodos de Pesquisa Social. Petrópolis, RJ: Vozes, 2015.

VEIGA, J.E. Desenvolvimento sustentável: o desafio do século XXI. Rio de Janeiro: Editora Garamond, 2005. 